\title{
Improving the delivery of wagon shipments by mathematical-statistical methods
}

\author{
Jamshid Kobulov*, and Jamshid Barotov \\ Tashkent State Transport University, Tashkent, Uzbekistan
}

\begin{abstract}
The results of the analysis of the delivery time of loaded wagons were determined by mathematical-statistical methods. The delivery time of the wagon shipment was considered in the example of a shipment with a transport distance of 200,650, $1000 \mathrm{~km}$ of the processing process based on the mathematical-statistical method. According to the law of normal distribution, the accuracy of the approximation of the delivery time is determined by V.I. In an examination using the Romanovsky criterion, it was proved that it would be taken into account in the future. The proposed time delivery technology is based on illustrative data on the completion of a specific delivery time provided to the team by determining a coefficient that considers various factors for the next period, i.e., this coefficient determines the daily distance traveled by the wagon for the next period.
\end{abstract}

\section{Introduction}

Research work is being carried out worldwide to improve the organization of technological processes of transportation of railway sections and routes and the development of transport services, methods of analysis, and control of delivery times. In this regard, including the systematization of conditional and random factors affecting the timing of delivery of goods by rail and improving the technology of organization of the freight process based on the time spent on all operations with wagons, the timing of delivery, taking into account the technical equipment The development of computing software is one of the important tasks. At the same time, it is necessary to develop a mathematical model of the dependence of the daily travel time of wagons based on mathematical-statistical methods for the timely and reasonable reduction of downtime between wagons and technological operations.

\section{Materials and Methods}

The unit and sum of objects or events of the same type combined according to any common feature constitute a general set [4-6]. For example, we are interested in the timeliness of delivery of a particular type of shipment with moving content. This means that all the wagons in a particular shipment form a general complex.

\footnotetext{
* Corresponding author: jam.uzb@mail.ru
} 
The purpose of the observations is to study the properties of the objects of the general complex that interest us. This task would have been solved if it had been possible to study all the objects belonging to the general complex. Often, such research requires a lot of labor or material costs when the unit size is large. In these cases, a limited number of objects are randomly selected for observation from the general set, using the sampling method of statistics, and then they are examined.

A set of objects randomly selected for observation is called a selected set or selection. Based on the found values of the selected set descriptions, the general thinks about the values of the set descriptions.

The following conditions must be met when making observations to ensure the reliability of these conclusions:

1) the sample must have a sufficient number of observation objects;

2) the objects of observation must reflect the general complex, i.e., have the characteristics of the general complex.

As the number of observations (sample size) increases, the characteristics of the sample complex (average value of the symptom, its variance, etc.) approach the characteristics of the main complex.

When processing statistical data on cargo transportation and analyzing them, the number of observations in the sample $\mathrm{n}$ can be found according to the following formula [3, 14]:

$$
n \geq \frac{X^{2}}{4 \cdot \mu^{2}}
$$

where $\mathrm{X}$ is the value obtained from the table of integral values of probabilities

$P=F(x)$ for the accepted reliability or depending on the level of reliability of the obtained results; $\mu$ is the accuracy required in this type of research.

In scientific research practice, it is often taken as $\mu=0.05, P=0.90$ [3]. The accepted reliability of the observations was $\mathrm{P}=0.90$, and the degree of accuracy in the study $\mu=0$; for the case assumed to be [1-2], we find $X=1$, accordingly. In this case:

$$
n \geq \frac{1,65^{2}}{4 \cdot 0,05^{2}}=273
$$

Therefore, the sample size (total number of observations) must be at least 273 objects.

For the sample to accurately reflect the properties of the general complex, it is necessary to obtain each observation unit completely randomly, without selecting approximately.

If the objects of the general complex are moving and their random appearance is ensured, then any sequence (sequence) consisting of $\mathrm{n}$ objects is included in the sample. For example, the time required for the arrival of any cargo in a wagon shipment is random, and a sample of $n$ consecutive shipped wagons can be obtained to determine the average delivery time.

According to mathematical-statistical methods $[6,8,15]$, the width of the sample is determined as follows, based on the number of objects in the general complex $(n)$ :

$$
C=\frac{t_{\max }-t_{\min }}{K}
$$


Table 1. Results of processing of wagon delivery based on the law of normal distribution (for a case with a delivery distance of $650 \mathrm{~km}$ )

\begin{tabular}{|c|c|c|c|c|c|c|c|c|c|c|}
\hline $\mathrm{T} / \mathrm{p}$ & & & 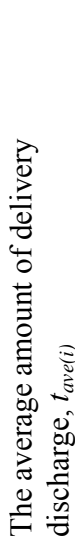 & 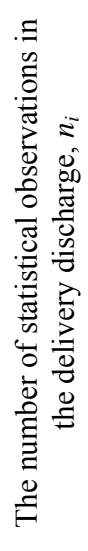 & 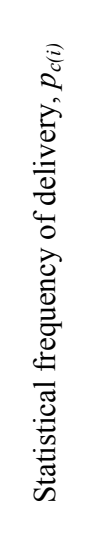 & : & 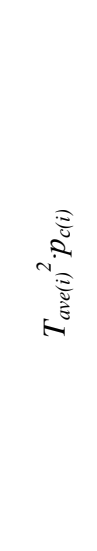 & 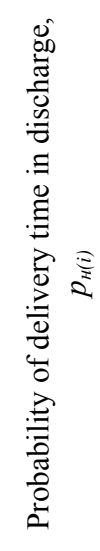 & 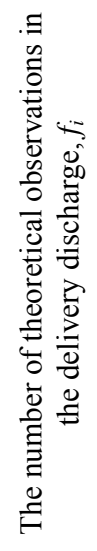 & $\frac{\left(n_{i}-f_{i}\right)^{2}}{f_{i}}$ \\
\hline 1 & & & 3 & 4 & 5 & 6 & 7 & 8 & 9 & 10 \\
\hline 1 & 43.5 & 56.5 & 50 & 7 & $\begin{array}{c}0.022 \\
7\end{array}$ & 1.14 & 56.75 & 0.0238 & 7.33 & 0.015 \\
\hline 2 & 56.5 & 69.5 & 63 & 22 & $\begin{array}{c}0.071 \\
4\end{array}$ & 4.50 & $\begin{array}{c}283.3 \\
9\end{array}$ & 0.0599 & 18.45 & 0.683 \\
\hline 3 & 69.5 & 82.5 & 76 & 35 & $\begin{array}{c}0.113 \\
6\end{array}$ & 8.63 & $\begin{array}{c}656.1 \\
5\end{array}$ & 0.1161 & 35.76 & 0.016 \\
\hline 4 & 82.5 & 95.5 & 89 & 58 & $\begin{array}{c}0.188 \\
3\end{array}$ & $\begin{array}{c}16.7 \\
6\end{array}$ & $\begin{array}{c}1491 . \\
52\end{array}$ & 0.1743 & 53.68 & 0.347 \\
\hline 5 & 95.5 & $\begin{array}{c}108 . \\
5\end{array}$ & 102 & 67 & $\begin{array}{c}0.217 \\
5\end{array}$ & $\begin{array}{c}22.1 \\
9\end{array}$ & $\begin{array}{c}2262 . \\
87\end{array}$ & 0.2021 & 62.25 & 0.363 \\
\hline 6 & $\begin{array}{c}108 . \\
5\end{array}$ & $\begin{array}{c}121 . \\
5\end{array}$ & 115 & 48 & $\begin{array}{c}0.155 \\
8\end{array}$ & $\begin{array}{c}17.9 \\
2\end{array}$ & $\begin{array}{c}2060 . \\
46\end{array}$ & 0.1813 & 55.84 & 1.101 \\
\hline 7 & $\begin{array}{c}121 . \\
5\end{array}$ & $\begin{array}{c}134 . \\
5\end{array}$ & 128 & 36 & $\begin{array}{c}0.116 \\
9\end{array}$ & $\begin{array}{c}14.9 \\
6\end{array}$ & $\begin{array}{c}1915 . \\
29\end{array}$ & 0.1258 & 38.75 & 0.195 \\
\hline 8 & $\begin{array}{c}134 . \\
5\end{array}$ & $\begin{array}{c}147 . \\
5\end{array}$ & 141 & 20 & $\begin{array}{c}0.064 \\
9\end{array}$ & 9.15 & $\begin{array}{c}1290 . \\
28\end{array}$ & 0.0675 & 20.79 & 0.030 \\
\hline 9 & $\begin{array}{c}147 . \\
5\end{array}$ & $\begin{array}{c}160 . \\
5\end{array}$ & 154 & 9 & $\begin{array}{c}0.029 \\
2\end{array}$ & 4.50 & $\begin{array}{c}692.5 \\
1\end{array}$ & 0.0280 & 8.62 & 0.016 \\
\hline 10 & $\begin{array}{c}160 . \\
5\end{array}$ & $\begin{array}{c}173 . \\
5\end{array}$ & 167 & 6 & $\begin{array}{c}0.019 \\
5\end{array}$ & 3.26 & $\begin{array}{c}543.8 \\
4\end{array}$ & 0.0090 & 2.77 & 3.759 \\
\hline sum & --- & ---- & --- & 308 & $\begin{array}{c}1.000 \\
0\end{array}$ & $\begin{array}{c}102 . \\
99\end{array}$ & $\begin{array}{c}11253 \\
.05\end{array}$ & 1.0000 & 304 & 6.52 \\
\hline
\end{tabular}

Depending on the width of the sample. its discharge is determined as follows:

$$
C=\frac{t_{\max }-t_{\min }}{K}
$$


where $t_{\max }, t_{\min }$ is the largest and smallest value, respectively, between observations. In our case, the maximum and minimum amount of time spent on delivering the wagon, respectively, hours.

We consider the fulfillment of the delivery time of a wagon shipment on the example of a shipment with a transport distance of $650 \mathrm{~km}$ based on a mathematical-statistical method. (1) In general, the number of shipments under surveillance should be at least 273 . The total number of statistical data studied in the dissertation is 308 . This, in turn, indicates that the selected data is sufficient. Hence, it is possible to determine the sampling width based on (2);

$$
K=(1+3,322 \cdot \ln (n))=9,27
$$

The maximum and minimum time spent delivering the wagon between observations was 169 and 50 hours, respectively. Hence, the sampling discharge can be determined based on (3).

$$
C=\frac{t_{\max }-t_{\min }}{K}=\frac{169-50}{9,27}=12,84 \approx 13, \min
$$

We define the limits of the supply discharge. The research process in all mathematicalstatistical methods is performed based on Table 1. In this case, the small limit value of the first discharge is determined as follows (Table 1, column 2).

$$
h_{1 \min }=t_{\min }-\frac{C}{2}=50-\frac{13}{2}=43,5, \min
$$

Hence, the large marginal value of the first discharge is equal to

$$
h_{1 \max }=t_{1 \min }+C=43,5+13=56,5, \min
$$

Thus, the boundaries of the first discharge lie in the following intervals: $43.5 \div 56.5$. Correspondingly, the boundaries of the second discharge are in the range of $56.5 \div 69.5$, the boundaries of the third discharge are in the range of $69.5 \div 82.5$, and so on, lies.

The average amount of delivery discharge (Table 1, column 3 ) is determined as follows:

$$
h_{\text {ave }(i)}=t_{\min (i)}+\frac{t_{\max (i)}}{2} \text {, hour }
$$

According to (3.5), the average quantity in the first category of delivery is 50 , the average quantity in the second category is 60 , and so on.

The number of statistical observations in the delivery batch (Table 1. column 4), i.e., the completion of the delivery time corresponding to each batch, can be determined using the COUNT IF function of Microsoft Excel

The statistical frequency of delivery (Table 1, column 5) is determined as follows:

$$
P_{i}=\frac{n_{i}}{\sum_{i=1}^{j} n_{i}}
$$


For example, the statistical frequency of delivery in the first category is $7 / 308=0.0227$, and so on.

The statistical average, which characterizes the state of the statistical distribution series, i.e., the statistical average of the delivery time in the studied case, is determined as follows [3-10]:

$$
t_{\text {ave }}=\sum_{i=1}^{j} t_{\text {ave }(i)} P_{c(i)}, \text { hour }
$$

here $i$ is discharge number $(i=1.2 \ldots j)$.

Thus, according to (7), the statistical average amount of delivery time is 103 hours (Table 1, column 6).

The statistical variance characterizing the distribution of the distribution series, i.e., the statistical variance of the delivery time in the studied case, is determined as follows:

$$
D_{t}=\sum_{i=1}^{j} t_{\text {ave }(i)} P_{c(i)}-t^{2} \text { ave }, \text { hour }^{2}
$$

Hence, according to (3.8), the statistical variance of delivery time is 646 hours $^{2}$.

The statistical standard deviation, which characterizes the absolute deviation of the statistical series, i.e., the statistical standard deviation of the delivery time in the studied case, is determined as follows:

$$
\sigma_{t}=\sqrt{D_{t}}, \text { hour }
$$

Hence, according to (9), the statistical mean square deviation of the delivery time is 25.4 hours.

\section{Results and Discussion}

Based on columns 3 and 5 of Table 1, we present the observational data in the form of a histogram (Figure 1). After calculating the numerical descriptions of the statistical series, we proceed to select the distribution curve that describes this distribution relatively fully. The distribution corresponding to this curve is called the theoretical distribution [10-17].

The above shows that the fulfillment of the delivery times of wagon shipments can be determined based on the law of normal distribution.

The choice of a law that describes the statistical distribution of a random value with sufficient accuracy is made based on the physical nature of the process or event under study. In this case, the appearance of the histogram or distribution polygon and the numerical descriptions of the statistical series may serve as additional features. For example, for the law of normal distribution of a random value, the whole spread is placed on the plot $t_{\text {ave }} \mp 3 \sigma_{t}$ (with an accuracy of up to one percent) [18-20].

The coordinates of the theoretical curve of random value distribution are calculated by finding the probability that the random value falls into a certain interval, i.e., the probability of delivery in the studied case in the discharge (Table 1, column 8).

Since the appearance of the polygon of the histogram in Fig. 1 describes the law of 
normal distribution. for the law of normal distribution of a random value (Fig. 1, red curve), the probability of its falling into a certain interval $\left(p_{u(i)}\right)$ is determined by the following formula:

$$
P\left(h_{i(\min )} \leq p_{H(i)} \leq h_{i(\max )}\right)=F\left(h_{i(\max )}\right)-F\left(h_{i(\min )}\right)(10)
$$

where $F\left(h_{i}\right)$ is normal distribution law function.

$$
\mathrm{F}(\mathrm{h})=\frac{\left(\int_{0}^{h} e^{\frac{-h^{2}}{2}} d x\right)}{\sqrt{2 \pi}}
$$

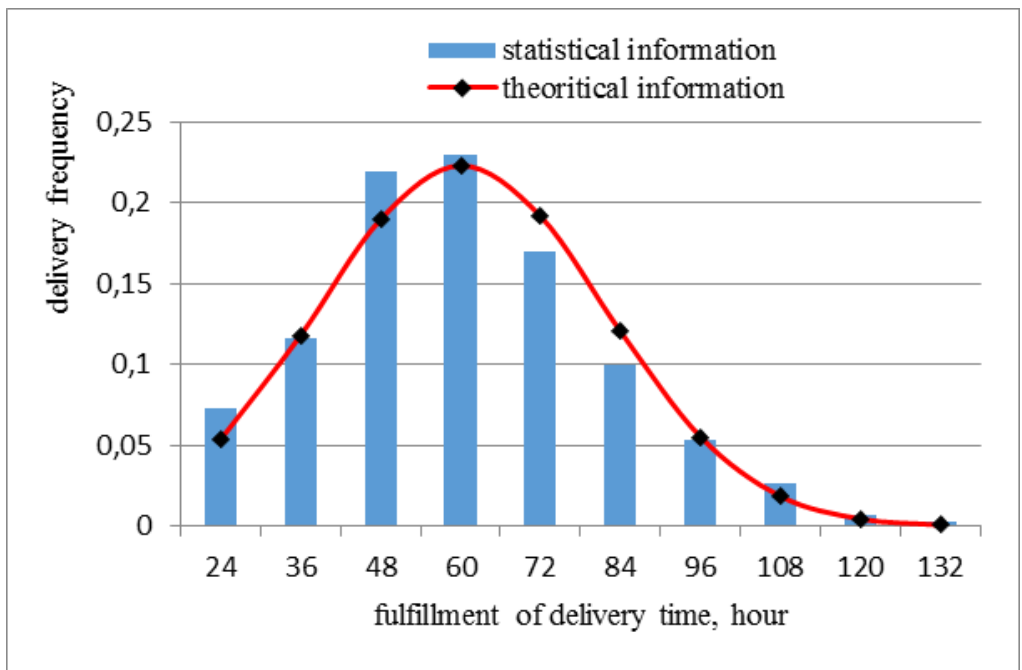

Fig.1. View of the results of processing of wagon delivery based on the law of normal distribution of the deadline for delivery (for cases where the delivery distance is $650 \mathrm{~km}$ )

F (h) values were determined using Mathcad. In this case, the probability of fulfillment of the delivery time corresponding to the first category in the discharge was determined following formulas (10) and (11) (Table 1, column 8) as follows:

$$
P\left(43,5 \leq p_{H(i)} \leq 56,5\right)=F(56,5)-F(43,5)=-0,4667-(-0,4905)=0,0238
$$

The probability in the discharge that the delivery time corresponding to the second discharge is met:

Equals to $P\left(56,5 \leq p_{H(i)} \leq 69,5\right)=F(69,5)-F(56,5)=-0,4068-(-0,4667)=0,0599$

The accuracy of the approximation of the delivery time according to the law of normal distribution K. Pearson was examined according to the criterion of consent (consent criterion $\chi^{2}$ (xi-square)).

$\chi^{2}$ is the value determined by the following formula (Table 3.1 , column 10 ). 


$$
\chi^{2}=\sum_{i=1}^{j} \frac{\left(n_{i}-f_{i}\right)^{2}}{f_{i}},
$$

where $f_{i}$ is the theoretical probability of the random variable being in the i-interval, the number of theoretical observations in the delivery discharge in the studied case (Table 1, column 9).

As shown in Figure 1, the statistical and theoretical distributions are close to each other. The results obtained from the statistical data are almost identical to those calculated according to the laws of normal distribution [12-13].

Statistical data and approximations of the correlation between the theoretical normal distribution curve V.I. were performed according to the Romanovsky criterion [20]. V.I. According to Romanovsky's rule:

$$
\frac{\chi^{2}-r}{\sqrt{2 r}} \leq 3
$$

if so, the adopted distribution law is considered to describe and describe the statistical distribution in a satisfactory manner.

where $r$ is the number of degrees of freedom:

$$
\mathrm{r}=\mathrm{k}-\mathrm{s}
$$

where $k-$ is the number of group intervals;

$S-$ is the number of independent (non-dependent) conditions (assumed to be for normal distribution [13-20]).

According to the law of normal distribution, the accuracy of the approximation of the delivery time is determined by V.I. During the examination using the Romanovsky criterion, the conditions of formula (13) assumed the following values of $0.78<3$. This, in turn, indicates that the approximation of the delivery time according to normal distribution law does not contradict this observation.

As shown in Figures 2-3, the statistical and theoretical distributions are close to each other. The results obtained from the statistical data are almost identical to those calculated according to the laws of normal distribution [9]. 


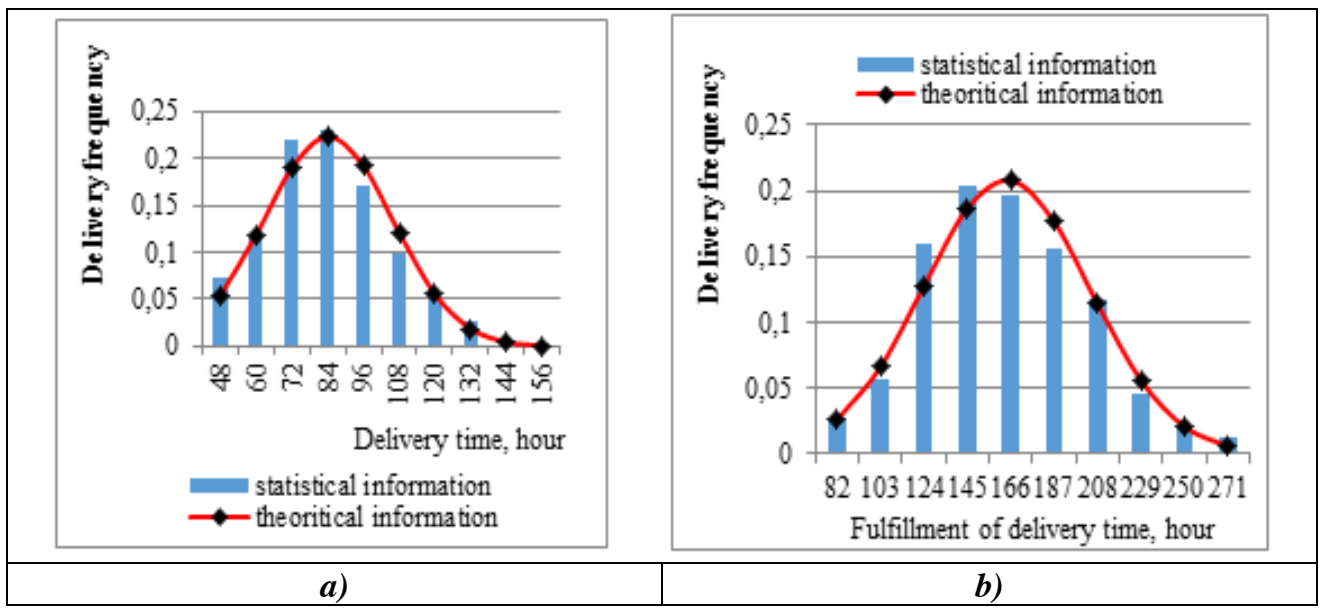

Fig. 2. a) View of the processing results based on the law of normal distribution of the deadline for delivery of wagons (for cases where the distance of delivery is 200 kilometers). b) View of the processing results based on the law of normal distribution of the deadline for delivery of wagons (for cases where the distance of delivery is $1000 \mathrm{~km}$ ).

Development of technology for regulating the time of delivery of goods on the basis of the law of normal distribution.

The obtained results were processed by the method of mathematical statistics (Figure 3), and it was determined that the calculated values of the delivery times of the loads obtained based on the developed mathematical model, proposed mathematical expressions, and created software also obey the law of normal distribution. At the same time, the relative error between the statistical and calculated values of the delivery time of wagon shipments did not exceed $20 \%$. This demonstrated the reliability of the proposed method of determining the time of delivery of goods by rail.

Based on the above, the technology of standardization of delivery time based on normal distribution law was developed to justify the daily distance traveled by wagon shipments in the freight system (Figure 3).

\section{Conclusion}

In our proposed delivery time measurement technology, it is done by setting a coefficient that considers various factors for the next period based on illustrative data on the completion of a specific delivery time provided to the community, i.e., this coefficient is used to standardize the daily distance. 


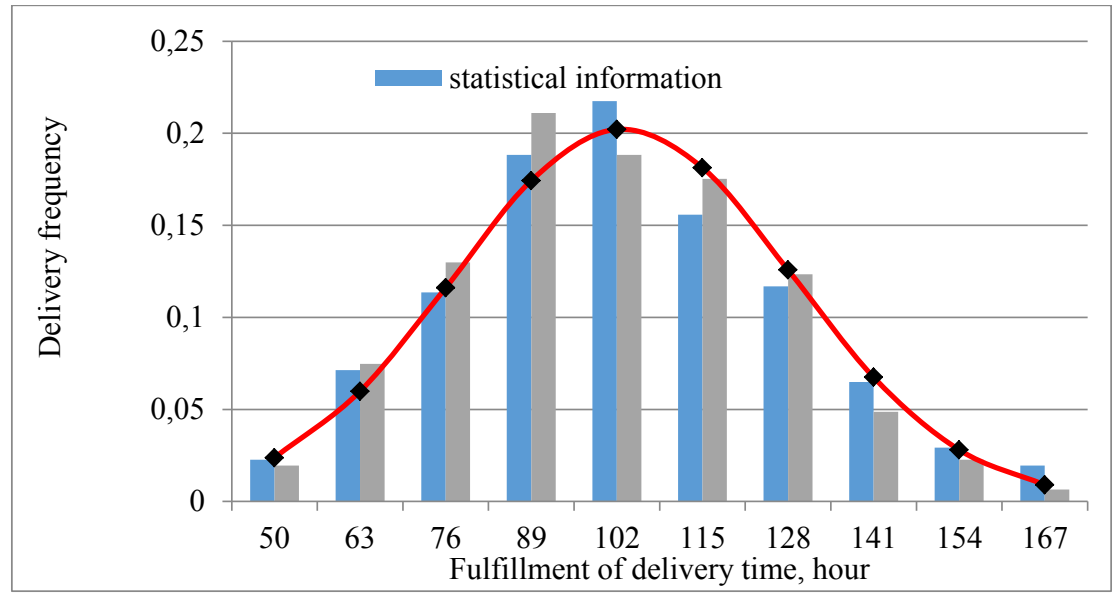

Fig.3. A fragment of the statistical and accounting data on the execution of the delivery time subject to the law of normal distribution.

The fulfillment of the delivery times of wagon shipments was processed by the method of mathematical statistics, and it was argued that it could be determined based on the law of normal distribution. In this case, the reliability of the approximation of the execution of the delivery time according to the law of normal distribution is K. Pearson was tested according to the consent criterion (the values of the consent criterion were less than 3 in all studied cases).

\section{References}

1. Romanovsky V.I. Mathematical statistics. Book 1. Foundations of the theory of probability and mathematical statistics. Tashkent: ANUZSSR. p 637. (1961).

2. Kudryavtsev. A.G. Kotenko. V.I. Badakh. E.Yu. Mokeichev. M.V. Strelkov - M, Educational and Methodological Center for Education in Railway Transport. p 263. (2009).

3. Kobulov J.. Barotov J. Method of Improvement of Efficiency Transportation Technology., International Journal of Recent Technology and Engineering (IJRTE). 8, (4). November. pp 7720-7726. (2019)

4. Kobulov J.R.. Barotov J.S. Rationing the time of departure of freight cars from stations and optimizing delivery times. Bulletin of Tashkent Institute of railway engineers. (2). pp 92-97. (2019).

5. Kobulov J.R.. Barotov J.S. Effektivnie sposobi ekspluatacii vagonov na jeleznodorojnom transporte Bulletin of Officil website of the Tashkent institut of design. construction and maintenance of automobile roads. (1). pp 92-97. (2019).

6. Butunov D.B. Barotov J.S.. Kobulov J.R.. Juraboev K.A. Determining the causes of losses affecting the amount of time the cars are at the station Bulletin of Officil website of the Tashkent institut of design. construction and maintenance of automobile roads. 2. pp. 89-98. (2019).

7. J.R. Kobulov. J.S. Barotov. The Development Model of Dispatching Wagons from Stations, International Journal of Advanced Research in Science. Engineering and Technology. 06 (5). pp 9460-9466. (2019). 
8. R. Kobulov. J.S. Barotov. The Method To Measure Time Spent On Wagons' Technological Operations at Stations / International Journal of Advanced Research in Science. Engineering and Technology. 6. (11). November. pp 11587-11594. (05.00.00; №8). (2019).

9. Kobulov J.R.. Mukhamedova Z.G.. Barotov J.S, Regulation of departure time of freight wagons from stations and optimization of delivery time of freight wagons from stations, Science research development Barcelona. 2019. 04 (1). pp 303 - 307. (2019).

10. Butunov D.B.. Barotov J.S.. Analysis of the transit time of transit cars with processing in the reception park and slides of the station. Bulletin of Turen polytechnic univerity in Tashkent 2019. (1). pp 115-119. (2019).

11. Kobulov J.R.. Barotov J.S. Justification of a rational method of using a refrigerated car In the collection, Logistics: modern development trends., Materials of the XVII International Scientific and Practical Conference. pp 228-230. (2018).

12. Kobulov J.R.. Barotov J.S. Effective organization of group train traffic, Collection of scientific papers "Current problems of operation and repair land vehicles. pp 29-33. (2020).

13. Mukhamedova. Z.G. Modelling of fluctuations in the main bearing frame of railcar, International Journal of Modern Manufacturing Technologies. VIII. (2). p. 48. (2016).

14. Z.G Mukhamedova. Mathematical Model for Calculation of Oscillations in the Main Bearing Frame of Railcar with Changing Stiffness and Physical Parameters., Journal of Siberian Federal University. Engineering \& Technologies. 10 (5). pp. 682 - 690. (2017).

15. Ilesaliev. D.. \& Avaz. M. Research package efficiency general cargo. International Journal of Engineering and Advanced Technology. 9(1). 6880-6884. doi:10.35940/ijeat.A2992.109119/(2019).

16. Z.G Mukhamedova. Reliability improvement of special self-propelled rolling stock based on its technical diagnostics., Journal of Critical Reviews. (7) (12). pp. 186 189. ISSN- 2394-5125. IF=1.091. (2020).

17. Z.G Mukhamedova. Diagnostics of asynchronous electric motors on the basis of spectral analysis of amplitude-modulated stator current., Scientific journal «European Sciences Review». Vienna. (7-8) 2018. P. 281 - 285. (2018)

18. R. Kobulov. J.S. Barotov. Organization of the movement of group trains to speed up the delivery of goods, Remote possibilities and scientific achievements. International scientific and practical conference. Ukraine. Kiev. June 2. pp 96-100. (2020)

19. J. Kobulov. J.S. Barotov. Improvement of customer service technology in reilway transport, TIRE journal of Sciences. (1), pp 41-46. (2019.)

20. Barotov J.S. Improving time norms when wagons are idle at the station, Collection of scientific publications of the international scientific and practical conference. Innovative development of science and education. - Pavlodar. pp 419-423. (2020). 